\title{
An investigation on the role of organizational climate on electronic learning
}

\author{
Hosseinali Aziziha $^{\mathrm{a}}$, Ashkan Faraji ${ }^{\mathrm{a}}$, Mahsan Hajirasouliha ${ }^{\mathrm{a}}$, Seyed Shahab Mousavi ${ }^{\mathrm{a}^{*}}$ and Milad \\ Isakhani Zakariab
}

${ }^{a}$ Department of Management and Accounting, South Branch, Islamic Azad University, Tehran, Iran ${ }^{b}$ Department of Management and Accounting, University of Tehran, Tehran, Iran

\section{H R O N I C L E}

\section{Article history:}

Received June 28, 2013

Received in revised format

19 October 2013

Accepted 20 December 2013

Available online

January 22014

Keywords:

Organizational atmosphere

Electronic learning

Banking industry

\section{A B S T R A C T}

This paper presents an empirical investigation on the effect of organizational climate on development of electronic learning in one of Iranian banks named Bank Maskan. In our survey, organizational characteristics include organizational structure, organizational communication, reward and promotion, organizational commitment, risk taking, organizational conflict and team-work. The proposed study uses two questionnaires, one for organizational climate and the other one for electronic learning, in Likert scale. Cronbach alpha for these two questionnaires are calculated as 0.79 and 0.86 , respectively. Using Pearson correlation ratio as well as stepwise regression analysis, the study determines that organizational structure, organizational communication, reward and promotion, organizational commitment, risk taking and team-work influence on electronic learning, positively.

\section{Introduction}

Organizational climate plays essential role on the success of organizations, an organization with good internal communication has better chance to share knowledge and it has better chance to remove any existing conflict (Owens \& Valesky, 1995; Robbins, 2003). There are literally various studies on relationship between organizational climate and other factors such as employee turnover. Suliman and Al Obaidli (2011), for instance, investigated the nature, strength and significance of the links between organizational climate and employee turnover. They reported that employees' perceptions of corporate climate had substantial impact in the rate of staff turnover. Organizational justice, as a component of corporate climate, detected to be the most influential factor in describing the variance in employee turnover. Allen (2003) investigated organizational climate and strategic change in higher education and discussed how a change on educational climate could make changes on educational development.

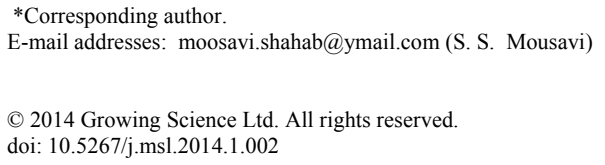


Nazari et al. (2011) aimed to investigate the effect of organizational culture and climate in supporting intellectual capital (IC) management systems. More specifically, it looks to study the relationship between organizational characteristics including culture and climate on one side and IC management systems in the Middle East (Iran and Lebanon) and Canada on the other side. They reported that both culture and climate had important impacts in developing management systems for IC. Besides, for country, when organizational climate improved, Middle Eastern respondents perceived an even bigger improvement in IC management systems compared with their Canadian counterparts.

Kuei et al. (1997) evaluated the relationship between quality management practices and organizational climate. The study applied two well-developed instruments to evaluate the relationship by performing the investigation among Taiwan's top 500 manufacturing corporations. They reported that high quality-tendency groups perceived a loose organizational structure, while medium qualitytendency groups perceived a more bureaucratic organizational structure.

Soeters and Schreuder (1988) reported the results of an empirical investigation of the relationship between national and organizational cultures at the firm level. They operationalized the concept of culture in six accounting companies using Hofstede's Value Survey Module. Three of these companies were local offices of international "Big Eight" accounting corporations with a strong U.S.orientation in their organizational philosophies and policies, whereas the other three firms were Dutch in origin. All six firms worked virtually primarily with Dutch employees. For two Hofstede's four cultural dimensions, they reported significant effects of the U.S. culture upon the organizational cultures of the Big Eight firms. Further analysis indicated that these results could rather be due to (self-)selection than to socialization mechanisms.

The recent advances on information technology have also contributed on development of electronic learning and most well-known universities have switched to offering different courses through electronic systems. People now have the opportunity to connect themselves with universities across the world without bothering about the boarders and people share their experiences on the advantages of learning over the cyber space (Bose, 2003).

\section{The proposed study}

This paper presents an empirical investigation on the effect of organizational climate on development of electronic learning in one of Iranian banks named Bank Maskan. In our survey, organizational characteristics include organizational structure, organizational communication, reward and promotion, organizational commitment, risk taking, organizational conflict and team-work. The proposed study uses two questionnaires, one for organizational climate, which is adopted from Arabac1 (2010) and the other one for electronic learning, in Likert scale. There were 42 questions associated with the proposed study of this paper where 4 questions are associated with risk taking, 5 questions covered organizational commitment, 4 questions were related to reward and promotion, 6 questions were associated with team-work, 3 questions studied organizational structure, 4 questions are related to organizational communication and 3 questions were associated with organizational conflict. In addition, 10 questions of the survey were associated with electronic learning. The sample size is calculated as follow,

$$
n=\frac{N \times z_{\alpha / 2}^{2} \times p \times q}{\varepsilon^{2} \times(N-1)+z_{\alpha / 2}^{2} \times p \times q},
$$

where $N$ is the population size, $p=1-q$ represents the yes/no categories, $z_{\alpha / 2}$ is CDF of normal distribution and finally $\varepsilon$ is the error term. Since we have $p=0.5, z_{\alpha / 2}=1.96$ and $N=350$, the number of sample size is calculated as $n=152$. Fig. 1 shows details of personal characteristics of the participants. 


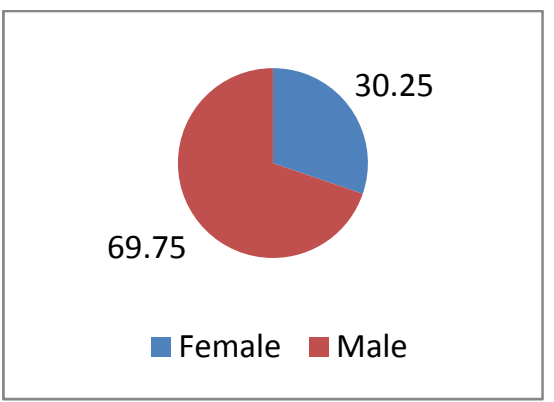

Gender

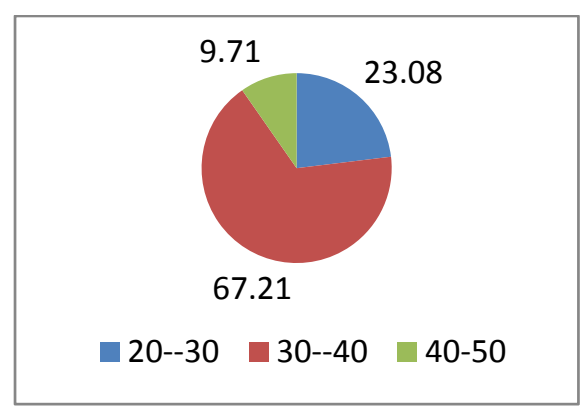

Age

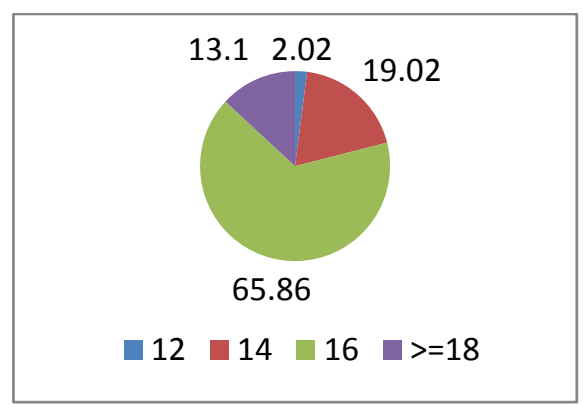

Years of education

Fig. 1. Personal characteristics of the participants

As we can observe from the results of Fig. 1, more participants in our survey were male. In addition, they were mostly middle age people and mostly university educated.

\section{The results}

In this section, we present details of our findings on testing the effects of seven organizational climate on electronic learning. We have performed normality test using Kolmogorov-Smirnov test and detected that all data were normally distributed. Therefore, we use Pearson correlation ratio to test the effects of various organizational climate on electronic learning summarized in Table 1 as follows,

\section{Table 1}

The summary of Pearson correlation between organizational climate and electronic learning

\begin{tabular}{llccc}
\hline Hypothesis & The relationship & $\mathrm{r}$ & Sig. & Result \\
\hline 1 & Risk taking and electronic learning & 0.246 & 0.000 & Confirmed \\
2 & Organizational commitment and electronic learning & 0.181 & 0.002 & Confirmed \\
3 & Reward and promotion and electronic learning & 0.416 & 0.001 & Confirmed \\
4 & Team work and electronic learning & 0.237 & 0.005 & Confirmed \\
5 & Organizational structure and electronic learning & 0.364 & 0.000 & Confirmed \\
6 & Organizational communication and electronic learning & 0.379 & 0.006 & Confirmed \\
7 & Organizational conflict and electronic learning & -0.158 & 0.185 & Rejected \\
\hline
\end{tabular}

The results of Table 1 show that electronic learning maintains positive and strong correlations with risk taking $(r=0.246$, Sig. $=0.000)$, organizational commitment $(r=0.181$, Sig. $=0.000)$, reward and promotions $(\mathrm{r}=0.416$, Sig. $=0.000)$, team-work $(\mathrm{r}=0.237$, Sig. $=0.000)$, organizational structure $(\mathrm{r}=0.364$, Sig. $=0.000)$, organizational communication $(\mathrm{r}=0.379$, Sig. $=0.000)$ and organizational conflict $(\mathrm{r}=0.379$, Sig. $=0.000)$. However, there is no meaningful relationship between organizational conflict and electronic learning. We have performed a stepwise regression analysis between electronic learning as dependent variable and organizational climate components as independent variables and the results are summarized in Table 2 as follows,

Table 2

The summary of stepwise regression model

\begin{tabular}{cccccc}
\hline Variables & Coefficient & Standard error & Standard coefficient & t-value & Sig. \\
\hline Intercept & 56.247 & 4.673 & & 13.985 & 0.000 \\
Reward & 0.539 & 0.295 & 0.375 & 2.492 & 0.006 \\
Structural organization & 0.512 & 0.251 & 0.324 & 2.352 & 0.000 \\
Risk taking & 0.486 & 0.228 & 0.273 & 2.122 & 0.019 \\
\hline
\end{tabular}


The results of Table 2 indicate that electronic learning has positive relationship with reward $(\beta=$ $0.375)$, standard organization $(\beta=0.324)$ and risk taking $(\beta=0.273)$.

\section{Conclusion}

In this paper, we have presented an empirical investigation to study the relationship between organizational climate and electronic learning. Using an existing questionnaire for organizational climate and designing a questionnaire for electronic learning, the survey has concluded that electronic learning had positive relationship with reward and promotion, standard organization and risk taking. The results of this survey are some what consistent with earlier findings reported by Arabac1 (2010) and Allen (2003).

\section{Acknowledgement}

The authors would like to thank the annonymous referees for constructive comments on earlier version of this paper, which have substantially contributed to the quality of the paper. We are also delighted for cooperation of Bank Maskan employees for cordially participating in our survey.

\section{References}

Allen, D. K. (2003). Organisational climate and strategic change in higher education: Organisational insecurity. Higher Education, 46(1), 61-92.

Arabac1, I. B. (2010). Academic and administration personnel's perceptions of organizational climate (Sample of Educational Faculty of Firat University). Procedia-Social and Behavioral Sciences, 2(2), 4445-4450.

Bose, K. (2003). An e-learning experience-a written analysis based on my experience in an elearning pilot project. Campus-Wide Information Systems, 20(5), 193-199.

Kuei, C. H., Madu, C. N., Lin, C., \& Lu, M. H. (1997). An empirical investigation of the association between quality management practices and organizational climate. International Journal of Quality Science, 2(2), 121-137.

Nazari, J. A., Herremans, I. M., Isaac, R. G., Manassian, A., \& Kline, T. J. (2011). Organizational culture, climate and IC: an interaction analysis. Journal of Intellectual Capital, 12(2), 224-248.

Owens, R. G., \& Valesky, T. C. (1995). Organizational behavior in education.

Robbins, S.P. (2003), Organizational Behavior, $10^{\text {th }}$ Edition, Printce Hall India.

Soeters, J., \& Schreuder, H. (1988). The interaction between national and organizational cultures in accounting firms. Accounting, Organizations and Society, 13(1), 75-85.

Suliman, A. M., \& Al Obaidli, H. (2011). Organizational climate and turnover in Islamic banking in the UAE. International Journal of Islamic and Middle Eastern Finance and Management, 4(4), 308-324. 